\title{
JIVS
}

\section{Successful treatment of cutaneous solid type adenocarcinoma with cryosurgery in a Pekingese dog}

Case Report

Volume: 3 , Issue: 3 December 2019

Pages: 85-88

\author{
Murat Kibar ${ }^{1}$, Zarima Jumakanova ${ }^{2}$ \\ 1.Hunting and Wild Lfe Medicine Programme, Artvin Vocational School, Artvin University, Artvin, Turkey. \\ 2.Department of Pathology, Faculty of Veterinary Medicine, Kyrgyz Turkish Manas University, Bishkek, Kyrgyzstan. \\ Findık M.: ORCID: 0000-0001-8879-4121, Jumakanova Z. ORCID: 0000-0001-5781-8004
}

\begin{abstract}
The aim of this study is to defined the treatment of cutaneous solid type adenocarcinoma in a Pekingese dog using cryotherapy. A 3.5 years old intact female Pekingese dog was referred to the small animal surgery clinic. The first neoplasm localization was dorsal to the vulva and the others were bilateral to the vulva. The shape of the nodules were circular. The nodule diameters were $1.8,1.5$, and $1.2 \mathrm{~cm}$. In cross section, the nodules were whitish-yellow in colour, of solid consistency, and characterized by thickening of the skin. The probe-based cryosurgical system was used for cryoablation, using local anesthetic as the interface for uniform freezing. Based on histopathological features, the dog was diagnosed with solid type perianal adenocarcinoma. In conclusion, cryosurgery can be a potent alternate treatment for pleasant, nodular perianal cutaneous adenocarcinoma in animals, particularly those not suited for operation, or whose owners refuse to have them undergo operation.
\end{abstract}

Keywords: Cryotherapy, tumor, dog

\section{Article History}

Received: 02.10.2019 Accepted: 24.12.2019 Available online: 26.12.2019

DOI: $10.30704 /$ http-www-jivs-net.628504

To cite this article: Kibar, M., \& Jumakanova, Z. (2019). Successful treatment of cutaneous solid type adenocarcinoma with cryosurgery in a Pekingese dog. Journal of Istanbul Veterinary Sciences. 3(3), 85-88, Abbreviated Title: J Ist Vet Sci

\section{Introduction}

Cryosurgery has been used for different benign, malignant, and premalignant cancers of dermis lesions by different practice methods, such as superficial spray, cotton-tipped applicator, intralesional, and cryoprobe (Kuflik and Kuflik, 2012; Lee et. al., 2016). When tissue is refrigerated, it is scarred by ice creation within the cells, vascular stasis and thrombosis, and the delivery of toxins and electrolytes. Extermination of malignant mass requires a resent tissue temperature of $-60^{\circ} \mathrm{C}$ (Kuflik, 2004; Ethan et. al., 2012).

Perianal glands in the dog are non-secretory, altered sebaceous glands indwelled around the anus and predisposed to tumor Moulton, 1990; Banks, 1993). The breeds most susceptible to perianal adenomas and carcinomas are the Siberian Husky,

*Corresponding Author: Murat Kibar

E-mail: muratkibartr@yahoo.com
Cocker Spaniel, Pekingese and, for adenocarcinomas, the Bulldog and the Siberian Husky (Merck, 2006). The aim of this study is to defined the treatment of cutaneous solid type adenocarcinoma in a Pekingese dog through cryotherapy.

\section{Case}

3.5 years old, intact female Pekingese dog weighing 6 $\mathrm{kg}$ observed to have three different sized nodules on her perianal and vulva region for 2 months was referred to the small animal surgery clinic (Figure 1). Blood values were normal (Table 1). The first neoplasm localization was dorsal to the vulva and the others were bilateral to the vulva, ruby-coloured, of firm consistency, and of luminous mucosal appearance. The shape of the nodules were circular. The nodule 


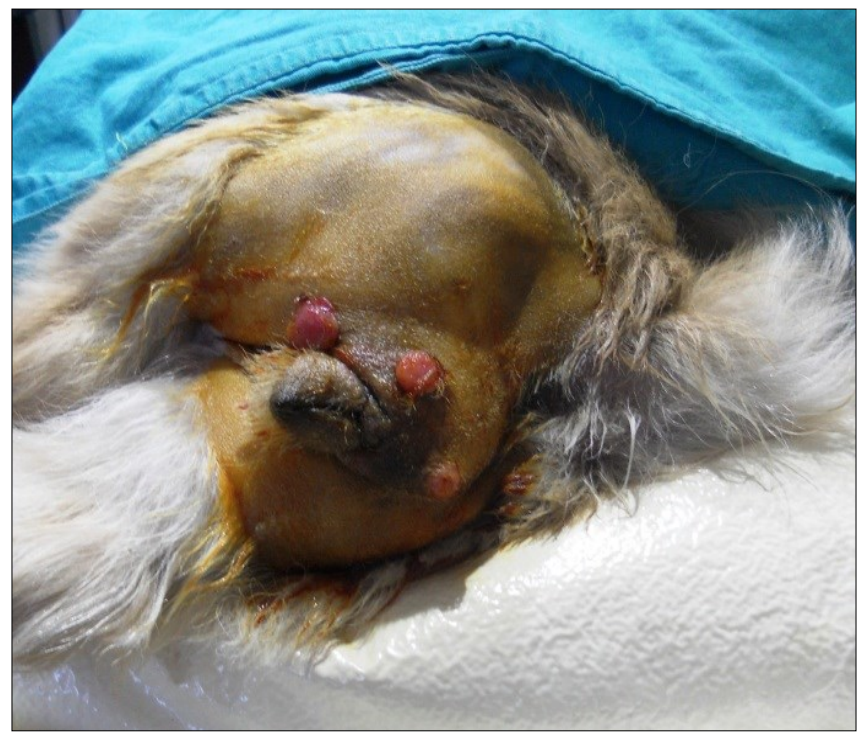

Figure 1. View of nodules in perianal region.

diameters were $1.8,1.5$, and $1.2 \mathrm{~cm}$. In cross section, the nodules were whitish-yellow in colour, of solid consistency, and characterized by thickening of the skin. The dog had not previously undergone surgical removal of tissue.

Table 1. Dog's blood values

\begin{tabular}{lc}
\hline Parameters & Values \\
WBC $\left(1 \times 10^{3} / \mu \mathrm{L}\right)$ & 11.3 \\
Lymphocyte $\left(1 \times 10^{3} / \mu \mathrm{L}\right)$ & 5.1 \\
Granulocytes $\left(1 \times 10^{3} / \mu \mathrm{L}\right)$ & 3.4 \\
HGB $(\mathrm{g} / \mathrm{dL})$ & 17.2 \\
HCT $(\%)$ & 54.3 \\
RBC $\left(1 \times 10^{6} / \mu \mathrm{L}\right)$ & 7.77 \\
MCV $(\mathrm{fL})$ & 70.0 \\
PLT $\left(1 \times 10^{3} / \mu \mathrm{L}\right)$ & 613 \\
\hline
\end{tabular}

The dog was premedicated with xylazine $\mathrm{HCl}(2 \mathrm{mg} \mathrm{kg}-$ 1, IM, Alfazin ${ }^{\circledast}$, Turkey). The probe-based cryosurgical system (Üzümcü, Istanbul, Turkey) was used for cryoablation using a local anesthetic (Industrial Ave, Molendinar, Australia) as the interface for uniform freezing. This system was comprised of a tube of liquid nitrogen $\left(-195^{\circ} \mathrm{C}\right)$ and a probe (Figure 2 ).

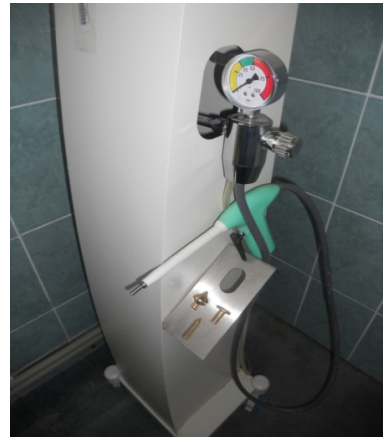

Figure 2. View of criosurgery equipment.
A probe with cytotherapeutic zones of $2 \mathrm{~cm}$ diameter was used in the study. The probe delivered liquid nitrogen, which did not come into contact with the ablated tissue. Being closed to liquid nitrogen flow allows for the thawing effect in the frozen cavity. Three cycles of freezing and thawing were induced, with the skin area being observed throughout (Figure 3).

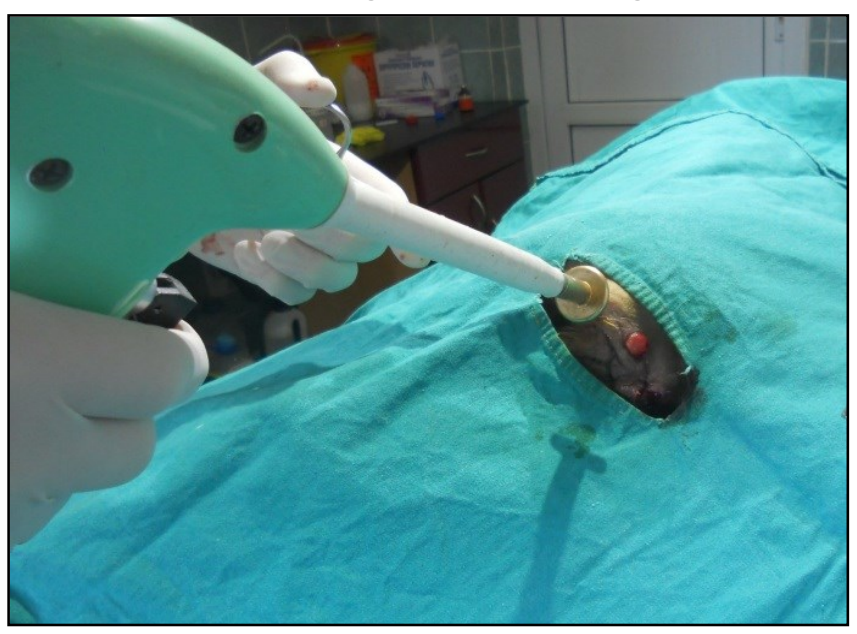

Figure 3. Application of cryoprobe to mass.

Freezing time was about 30 to 60 seconds. This was accomplished by ice creation over the whole tumor with at minimum 5-mm of independent margins (Figure 4). Technical achievement was noted as an elongation of the ice ball going further the tumor margin and post-ablation views indicating no contrast rise in the field of the original tumor 6 months following the primary procedure. Postoperatively, the patient was administered intravenous antibiotics for $72 \mathrm{hr}$. No visible tumor was defined by day 45 , and no recurrence was observed till 2 years.

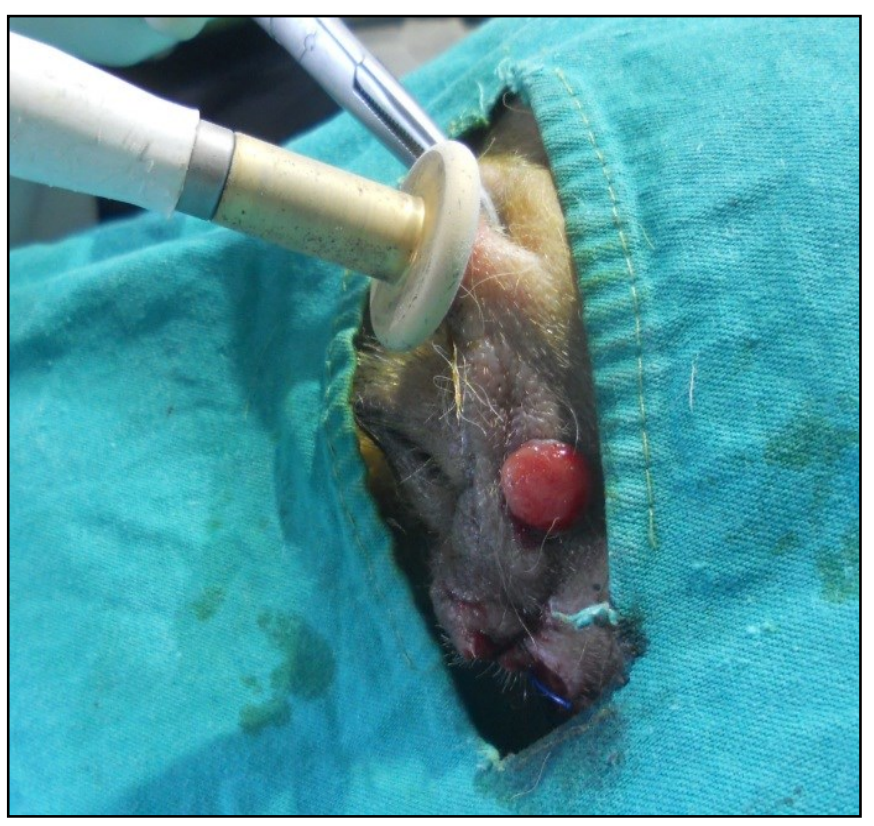

Figure 4. View of the ice formation of the whole tumor. 

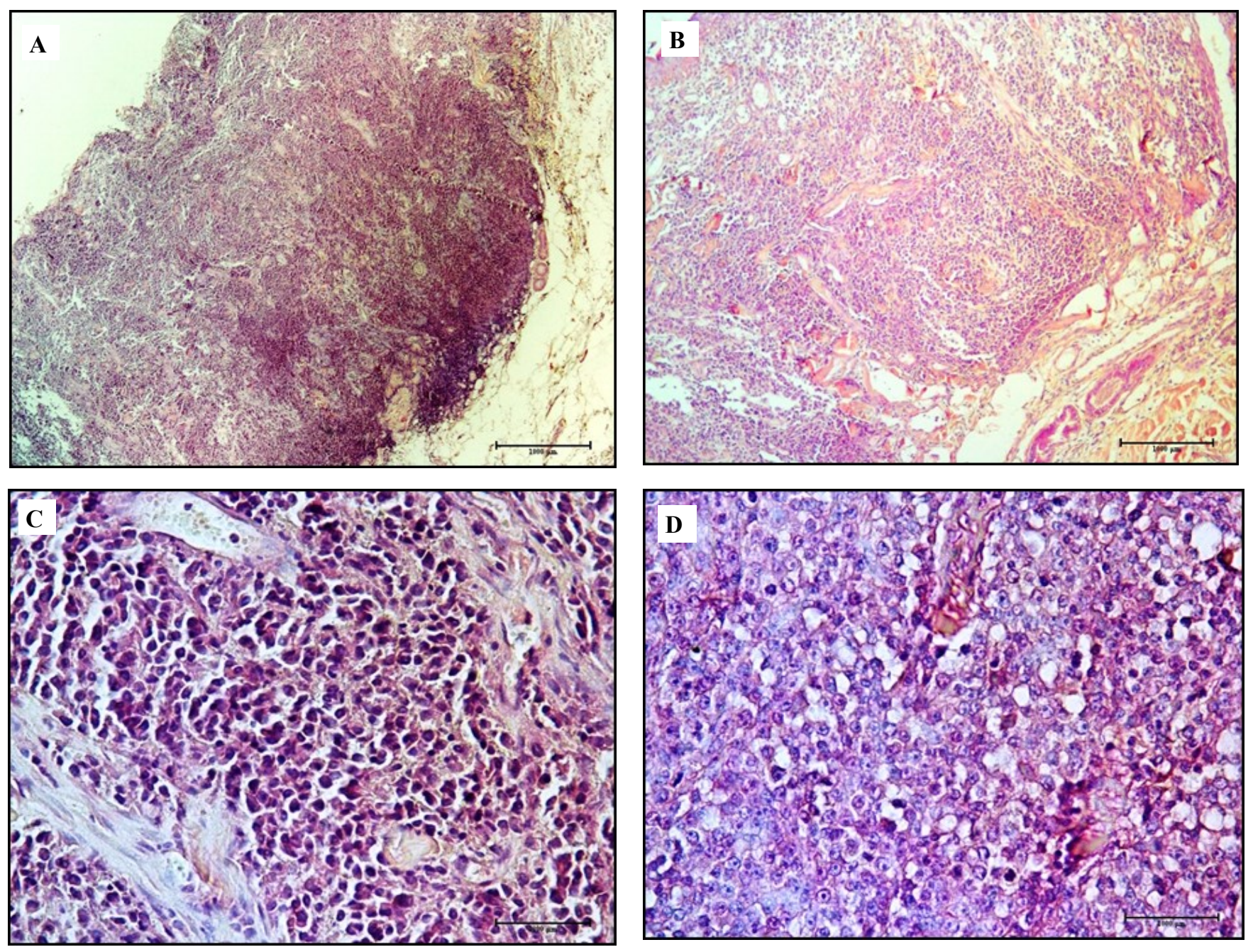

Figure 5. Histopathological sections of circumanal nodules in female Pekingese dog.

H\&E. Barr $=500 \mu \mathrm{m}$. (A) Epidermis, dermis and hypodermis structures destroyed. (B) Polymorphic, polyhedral cells organized in solid pattern and surrounded with massive connective tissue. (C, D) Tumour lobules observed well and they are separated with vast connective tissue. The lobes consist of the cells form solid sheets; have not abundant cytoplasm, quite pale, the nuclei are round with coarse chromatin and existence of one or more, but regular nucleoli. There is not a lot of anisocytosis, anisokaryosis and anisonucleoliosis and presence of frequent mitosis.

The obtained nodular tissues was fixated in $10 \%$ of neutral formalin. The tissue was processed and established in paraffin wax. Edges 4-5 $\mu \mathrm{m}$ thick were cut from the block and mounted with entellan Neu (Merck, Darmstat, Germany). For histopathological examination, edges were painted with routine hematoxylin and eosin.

This study describes the removal of 3 nodular adenocarcinoma in a patient who was successfully treated by cryoablation without complication. The histopathological examination showed that the layers of dermis and hypodermis were disturbed, and there was a bounded tumor nodule surrounded by massive fibrovascular stroma. Based on histopathological features, it was diagnosed as solid type perianal adenocarcinoma (Figure 5).

\section{Discussion and Conclusion}

The tumor varied from rosette, solid, to tubular types by histologically. The solid subtype consisted of sheets of neoplastic cells subdivided into thin bands of fibrous tissue, but lacked glandular structures (Schulman, 1998). According the histopathological results, this case demonstrated characteristics of solid type adenocarcinoma with vast connective tissue, grid -type reticulation, and frequent mitosis. Tumor cells originated from the glandulocytes of the derma.

This type of tumor is most often seen in dogs between ages 5 and 14 (median 9 years) (Schulman, 1998; Turek et. al., 2003). However, in this case, the dog was 3.5 years old; according the literature, affected dogs tend to be older. The breeds most susceptible to perianal adenomas are the Siberian Husky, Cocker Spaniel, Pekingese and, for adenocarcinomas, the Bulldog and Siberian Husky (Merck, 2006).

There are several great-scale studies display elevated therapy rates of cryosurgery for nonmelanocytic cancers of dermiş (Lee et. al., 2016). 
In the report by Kuflik (2004), most cases were cured by curettage before use of the open spray technique, with a treatment rate of $99 \%$ in 522 cases. The 5 -year therapy rate in squamous cell carcinoma lower than 2 $\mathrm{cm}(\mathrm{n}=134)$ was $100 \%$ (Lee et. al., 2016).

Our research is restricted to one case. However, cryoablation seems simple, suitable, and safe for advanced nodular tumors. All tumor masses ablated after 2 cryoprobe treatments in the patient. Cryosurgery may ensure long-term remission as integrate clinical alleviation was defined in the case till 2 years of follow-up. Also, the esthetic outcome was too extremely satisfactory. However, it should be determined that cryosurgery may not be acceptable for patients with tumors found in locations and conditions where cryosurgery is not useful, such as the eyelash region or medial canthus, to avoid damage of ocular tissue or canaliculus, acral part in patients with poor circulation or poor healing, or in locations where the nerves are quite outcrops, as this provides the potential risk of nerve wound. Moreover, cryosurgery is excellent to radiotherapy for its plainness, and as it is free of complications such as lymphedema, secondary cancer, and radiodermatitis (Samstein et. al, 2014).

In conclusion, cryosurgery can be an influential alternative cure for pleasant, nodular perianal cutaneous adenocarcinoma in animals, particularly those not suited for operation, or whose owners refuse to have them undergo operation Larger, controlled, and multi-disciplinary studies are required to approve its efficacy and safety.

\section{Conflict of interest}

The authors declare that there was not any conflict of interest.

\section{References}

Banks, W. J. (1993). Applied veterinary histology. St. Moulton, J. E. (1990). Tumors in domestic animals. Louis. US: Mosby. Berkeley, US: University of California Press.

Ethan, E., Zimmerman, M., \& Crawford, P. (2012). Samstein, R. M., Ho, A. L., Lee, N. Y., \& Barker C. A. Cutaneous Cryosurgery. American family physician, 86, 1118-1124.

Kuflik, E. G., \& Kuflik, H. J.(2012). Cryosurgery. In J. L. Bolognia, J. L. Jorizzo, J. V. Schaffer (Ed). Dermatology. 3rd ed. (pp. 2283-2291). Amsterdam, Schulman, F. Y. (1998). Tumors with adnexal Netherlands: Elsevier.

Kuflik, E. G. (2004). Cryosurgery for skin cancer: 30year experience and cure rates. Dermatologic surgery, 30, 297-300.

Lee, C. N., Pan, S. C., Lee, J. Y. Y., \& Wong, T. W. (2016). Successful treatment of cutaneous squamous cell carcinoma with intralesional cryosurgery. Medicine, 95, 39 (e4991).

Merck. (2006). Hepatoid gland tumors. Merck (2014). Locally advanced and unresectable cutaneous squamous cell carcinoma: outcomes of concurrent cetuximab and radiotherapy. Journal of skin cancer, 2014: 284582.

differentiation. In Fy Schulman, (ed), : Histological classification of epithelial and melanocytic tumors of the skin of domestic animals. 2 nd ed. Armed forces institute of pathology, Washington,

Turek, M. M., Forrest, L. J., Adams, W. M., Helfand S. C., \& Vail, D. M. (2003). Postoperative radiotherapy and mitoxantrone for anal sac adenocarcinoma in the dog: 15 cases (1991-2001). Veterinary and comparative oncology, 1,94-104. veterinary manual. Retrieved 2007-03-27. 